\title{
VALIDATION AND DEVELOPMENT OF DISCHARGE EQUATIONS FOR 3D PRINTED FLUMES FOR FLOW MONITORING
}

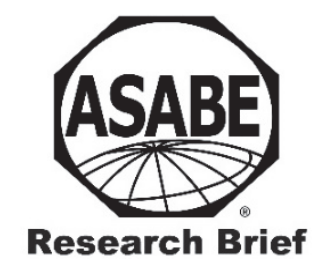

\author{
Farhana Akhter ${ }^{1}$, John T. McMaine ${ }^{1, *}$, Alex J. McLemore ${ }^{2}$, Morghan J. Hurst ${ }^{1}$ \\ ${ }^{1}$ Department of Agricultural and Biosystems Engineering, South Dakota State University, Brookings, South Dakota, USA. \\ ${ }^{2}$ Department of Agriculture, Abraham Baldwin Agricultural College, Tifton, Georgia, USA. \\ * Correspondence: john.mcmaine@sdstate.edu.
}

\section{HighLIGHTS}

- Two different configurations of 3D printed flumes of two different materials were tested for accuracy and variability.

- Discharge equations were developed for 3D printed $0.122 \mathrm{~m} \mathrm{HS}$ and $0.102 \mathrm{~m}$ Palmer-Bowlus flumes.

- 3D flumes are accurate and show no statistical variability between prints, providing a low-cost flow measurement tool.

\begin{abstract}
Flumes are specially shaped, engineered structures that have been used widely for measuring flow. Flumes are typically fabricated from aluminum or fiberglass; however, these types of flumes can be costly if purchased commercially and may lack machine precision if custom fabricated. This limits availability for widespread monitoring by smaller municipalities, engineering firms, or researchers with limited budgets. Using $3 D$ printing technology (additive manufacturing) to produce flumes is very cost-effective, but variability between flumes and materials has not been tested, and discharge equations have not been developed for $3 D$ printed flumes. In this study, a laboratory-scale setup was used to develop discharge equations for two types of $3 \mathrm{D}$ printed flumes $(0.122 \mathrm{~m}$ HS flume and $0.102 \mathrm{~m}$ Palmer-Bowlus flume) made from two $3 D$ printing materials: polylactic acid (PLA) and polyethylene terephthalate glycol modified (PETG). Variability between the same type of flume and between different materials for the same type of flume was analyzed to evaluate the consistency of the discharge equation with flumes of the same type. Eight models were developed to fit each dataset (PLA, PETG, and combined PLA and PETG) for both flume types and evaluated for goodness-of-fit and information criteria (AIC and BIC for model parsimony) to select the discharge equation for each flume type. Discharge equations were consistent for the same type of flume across each print and across different print materials. The discharge equations of $3 D$ printed $0.122 \mathrm{~m}$ $H S$ flumes and $0.102 \mathrm{~m}$ Palmer-Bowlus flumes are $Q=0.45624 \times H^{2.351}$ and $Q=0.0001176+1.309 \times(H-0.0174625)^{2.235}$, respectively. The discharge equations of both flume types had $R^{2}$ adj values greater than $97 \%$ for the measured data of each individual flume. Both $3 D$ printed flumes were consistent in measuring flow and are suitable for hydrologic monitoring.
\end{abstract}

Keywords. 3D printing, Additive manufacturing, Discharge equation, Flume, Hydrologic monitoring.

$\mathrm{F}$ lumes are flow measurement devices shaped specifically to produce critical or super-critical flow by contracting the flume sidewalls or by sloping the flume floor (Kilpatrick and Schneider, 1983). Flow is measured indirectly by measuring the flow depth and calculating the flow with a stage-discharge equation. Flumes are commonly used to measure flow for various monitoring settings, such as agricultural runoff, urban stormwater, municipal storm sewers, and industrial discharge. Flumes made from fiberglass, steel, and aluminum are widely available but are often expensive, and their use makes large-scale

\footnotetext{
cC) $\$($ The authors have paid for open access for this article. This BY NC ND work is licensed under a Creative Commons AttributionNonCommercial-NoDerivatives 4.0 International License https://creative commons.org/licenses/by-nc-nd/4.0/

Submitted for review on 15 October 2020 as manuscript number NRES 14365; approved for publication as a Research Brief by the Natural Resources \& Environmental Systems Community of ASABE on 2 July 2021.
}

monitoring cost-prohibitive. Three-dimensional (3D) printing technology can be used to manufacture flumes at a very low cost; however, there has been no examination of the consistency of discharge equations with 3D printed flumes.

In this study, two types of flumes were considered (0.122 m HS flume and $0.102 \mathrm{~m}$ Palmer-Bowlus flume). The USDA Soil Conservation Service originally developed H, HL, and HS flumes for measuring flow from small watersheds (Gwinn and Parsons, 1976; Kilpatrick and Schneider, 1983). Among them, HS flumes are designed to measure low flows with a high degree of accuracy. The capacity of a range of sizes of HS flumes is 0.0024 to $0.023 \mathrm{~m}^{3} \mathrm{~s}^{-1}$ (Gwinn and Parsons, 1976). Gwinn and Parsons (1976) specified that the sidewalls of an HS flume are made to converge gradually in the downstream direction to increase the velocity of the flow while operating under free flow conditions to produce critical flow at the downstream end (Kilpatrick and Schneider, 1983). The Palmer-Bowlus flume was originally designed for use in sewer systems (Palmer and Bowlus, 1936), but it 
can be used in other open-channel settings. A PalmerBowlus flume is circular, or U-shaped from the outside, and it has a long throat section that is formed by constricting the sidewalls and raising the flume floor to produce critical flow (Ludwig and Parkhurst, 1974).

The main objective of this study was to provide guidance for printing and using 3D printed flumes in hydrologic monitoring applications and provide validation of discharge equations by analyzing the variability between flumes of the same type and print material and between flumes of different print materials. This study provides a methodology to develop discharge equations for 3D printed flumes, discharge equations for 3D printed $0.122 \mathrm{~m}$ HS flumes and $0.102 \mathrm{~m}$ PalmerBowlus flumes, and validation of the accuracy and repeatability of 3D printed flumes for use in flow measurement.

\section{Materials ANd Methods \\ EXPERIMENTAL SETUP}

A laboratory-scale setup was used to develop discharge equations for two types of flumes $(0.122 \mathrm{~m} \mathrm{HS}$ and $0.102 \mathrm{~m}$ Palmer-Bowlus) (fig. 1). Two variables were tested with two treatments for each print material (polylactic acid [PLA] and polyethylene terephthalate glycol modified [PETG]) and flume type (0.122 m HS and $0.102 \mathrm{~m}$ Palmer-Bowlus) and three replications (printed flumes) of each treatment. The flumes were printed using a CR-10 V2 3D printer (Creality, Shenzhen, China, $\pm 0.1 \mathrm{~mm}$ precision). All internal dimensions of each printed flume were measured using a Vernier caliper ( $0.0254 \mathrm{~mm}$ precision). Water was pumped by a variable-frequency drive pump from an open tank reservoir into one end of a rectangular wooden channel $(45.7 \mathrm{~cm}$ width, $91.4 \mathrm{~cm}$ length, $30.5 \mathrm{~cm}$ height). The water traveled through a flow straightener before entering the flume to ensure laminar flow entering the flume. The flow straightener was made of $2.54 \mathrm{~cm}$ diameter PVC pipe arranged in a honeycomb structure.

The discharge equation for each treatment and replication was developed using approximately 20 data points. For each measurement, the pump was set to provide a constant flow through the flume. The depth of water within the flume was measured with a point gauge. Water flowing through the flume was collected in an $18.9 \mathrm{~L}$ plastic bucket. A stopwatch was used to measure the time required to fill the bucket to a certain depth, and then the tared weight of the bucket was taken to calculate the mass flow rate at that constant flow rate. The temperature of the collected water was measured to determine the specific gravity of the water. These measurements were used to calculate volumetric flow rate (eq. 1):

$$
Q=\frac{M}{t \times \rho_{w}}
$$

where $Q$ is the flow rate $\left(\mathrm{m}^{3} \mathrm{~s}^{-1}\right), M$ is the mass of water $(\mathrm{kg})$, $t$ is the elapsed time (s), and $\rho_{w}$ is the density of water $\left(\mathrm{kg} \mathrm{m}^{-3}\right)$ at the measured temperature $\left(T,{ }^{\circ} \mathrm{C}\right)$. The volumetric flow rate was measured three times for each depth, and the flow rates were averaged to determine the depth and flow rate for that point.

\section{MODEL DEVELOPMENT}

Discharge equations were developed by comparing the measured data to previously published equations and using goodness-of-fit metrics to determine the best equation. First, a scatter plot (discharge vs. flow depth) of the measured data was developed and analyzed against previously published models for similar types of flume discharge data. Eight curve-fitting models were developed that expressed the relationship between the flow rate and the depth of water within the flumes. The least-square regression method was used to fit these models to the measured data. MATLAB R2019b (MathWorks, Natick, Mass.) was used to adjust the parameters of the developed models and determine the best model.

The goodness-of-fit of the eight models to their data was determined by calculating sum of squares error (SSE), adjusted $\mathrm{R}^{2}\left(\mathrm{R}^{2}{ }_{\mathrm{adj}}\right)$, and root mean square error (RMSE). The eight models had different numbers of parameters $(k)$. Typically, models that have a higher number of parameters result in a better goodness-of-fit; however, simple models are more likely to avoid overfitting. The Akaike information criterion (AIC, eq. 2) (Akaike, 1974), adjusted AIC (AIC $c$, eq. 3) (Hurvich and Tsai, 1989), and Bayesian information criterion (BIC, eq. 4) (Schwarz, 1978) were calculated for this study to make a quantitative model selection that included both parsimony and goodness-of-fit:

$$
\mathrm{AIC}=n\left[\ln \left(\frac{\mathrm{RSS}}{n}\right)\right]+2 k
$$

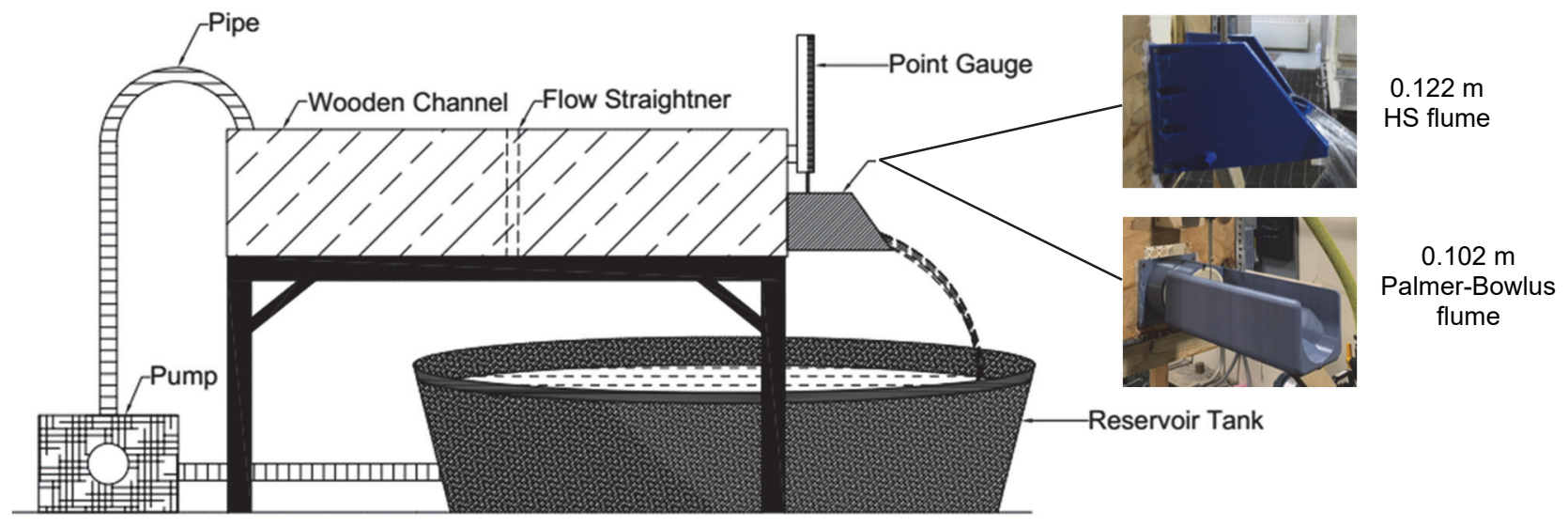

Figure 1. Schematic of experimental setup including pictures of flumes evaluated in the experiment. 
where AIC is the Akaike information criterion, $k$ is the number of fitted parameters including the error, RSS is the residual sum of squares of the model, and $n$ is the sample size.

$$
\mathrm{AIC}_{c}=\mathrm{AIC}+\frac{2 k(k+1)}{n-k-1}
$$

where $\mathrm{AIC}_{c}$ is the adjusted AIC for a small sample size (i.e., when the ratio of the number of data points to the number of parameters is less than 40), AIC is the Akaike information criterion, $k$ is the number of fitted parameters including the error, and $n$ is the sample size.

$$
\mathrm{BIC}=n\left[\ln \left(\frac{\mathrm{RSS}}{n}\right)\right]+2 \ln (n) k
$$

where BIC is the Bayesian information criterion, $k$ is the number of fitted parameters including the error, RSS is the residual sum of squares of the model, and $n$ is the sample size.

The AIC overestimates the required number of parameters, resulting in a more complex model, when the sample size is large (Kass and Raftery, 1995). Schwarz (1978) indicated that when the number of observations is large $(n \geq 8)$, $\mathrm{BIC}$ tends to select a simpler model than AIC. For these reasons, both AIC and BIC were used for the model comparison in this study. In most cases, the selected model ranked highest for both criteria. If the ranking did not agree for both criteria, the most parsimonious model was selected.

The AIC value of a candidate model quantifies the information loss, which represents the distance between the probability distribution of the true model and the probability distribution of the model under evaluation (Wagenmakers and Farrell, 2004). The lowest BIC value of a model indicates that the model has the highest posterior probability among the candidate models (Kass and Raftery, 1995). Hence, the model with the lowest AIC and BIC values was preferred in this study. The difference ( $\Delta$ in eq. 5 ) between each of the information criteria $\left(\mathrm{IC}=\mathrm{AIC}, \mathrm{AIC}_{c}\right.$, of $\left.\mathrm{BIC}\right)$ values of each model and the best model was calculated:

$$
\Delta_{i}=\mathrm{IC}_{i}-\mathrm{IC}_{\text {min }}
$$

where $\Delta_{i}$ is the difference between the information criteria values of model $i$ and the best model, $\mathrm{IC}_{i}$ is the information criterion value of model $i$, and $\mathrm{IC}_{\min }$ is the information criterion value of the best model. A model is considered as good as the best model when $\Delta_{i}$ is less than 2 (Burnham and Anderson, 2002; Richards, 2005; Symonds and Moussalli, 2011). Using the $\Delta_{i}$ value, the weights ( $w_{i}$ in eq. 6 ) and evidence ratio (ER in eq. 7) were calculated to measure the relative strength of each model (Burnham and Anderson, 2002; Wagenmakers and Farrell, 2004):

$$
w_{i}=\frac{\exp \left(-\frac{\Delta_{i}}{2}\right)}{\sum_{m=1}^{M} \exp \left(-\frac{\Delta_{m}}{2}\right)}
$$

where $w_{i}$ are the weights, $\Delta_{i}$ is the difference between the information criteria values of model $i$ and the best model, and $\Delta_{m}$ is the $\Delta$ value of model $m(m=1, \ldots, M)$ :

$$
\mathrm{ER}=\frac{\exp \left(-\frac{\Delta_{\text {best }}}{2}\right)}{\exp \left(-\frac{\Delta_{i}}{2}\right)}
$$

where ER is the evidence ratio, $\Delta_{\text {best }}$ is the $\Delta$ value for the best model, and $\Delta_{i}$ is the difference between the information criteria values of model $i$ and the best model. The Akaike weights $\left(\mathrm{AIC} w_{i}\right)$ and Schwarz weights $\left(\mathrm{BIC} w_{i}\right)$ both express the degree to which a model is the best model among a set of models. The $\mathrm{AIC} w_{i}$ and $\mathrm{BIC} w_{i}$ express the probability that model $i$ is the best model among the listed models (Wagenmakers and Farrell, 2004). The evidence ratio in terms of $\mathrm{AIC}\left(\mathrm{AIC} \mathrm{CR}_{\mathrm{ER}}\right)$ and $\mathrm{BIC}\left(\mathrm{BIC}_{\mathrm{ER}}\right)$ calculates how much better the best model is than model $i$ (Burnham and Anderson, 2002). The best model was selected based on the results of the Akaike and Bayesian information criteria. For each type of flume, three different discharge equations were chosen with three different sets of data: PLA, PETG, and both PLA and PETG. All three cases were compared against each individual flume dataset to test for variability between the different print materials and between different flumes of the same material.

\section{RESULTS AND DISCUSSION DESIGN OF FLUMES}

The internal dimensions of the 3D printed $0.12 \mathrm{~m} \mathrm{HS}$ flumes and $0.102 \mathrm{~m}$ Palmer-Bowlus flumes, as presented in figures 2 and 3, were the same for flumes of the same type (tables 1 and 2). Note that dimensions B, F, G, J, and K for the HS flume (table 1) and dimension B for the PalmerBowlus flume (table 2) were different between the printed flumes and published values. This was not due to printing inaccuracies but rather reflected a slight modification of the design to test the flexibility of the discharge equation development method.

\section{DEVELOPED MODELS}

From the developed models (table 3 ), discharge equations were selected for the three datasets (PLA, PETG, and combined PLA and PETG), and the full list of tested discharge equations is presented for the combined PLA and PETG dataset for both flume types in tables 4 and 5 .

The discharge equations developed in this study were also compared against published discharge equations (Bos, 1976; Walkowiak, 2006). Bos (1976) developed empirical discharge equations for the $0.122 \mathrm{~m}$ HS flume (eq. 8), which was considered for this study. According to Bos (1976):

$$
\log Q=-04361+2.5151\left(\log H_{a}\right)+0.1379\left(\log H_{a}\right)^{2}
$$

where $Q$ is the volumetric flow rate $\left(\mathrm{m}^{3} \mathrm{~s}^{-1}\right)$, and $H_{a}$ is the depth of water $(\mathrm{m})$. The equation developed by Walkowiak 


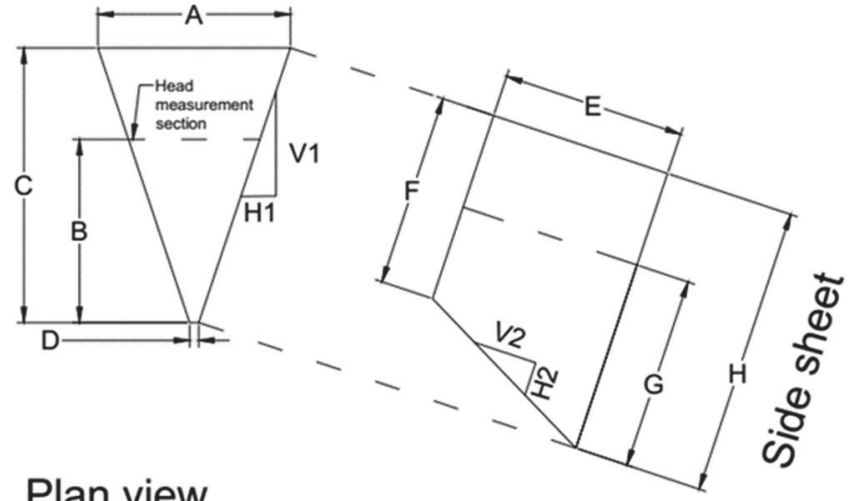

Plan view

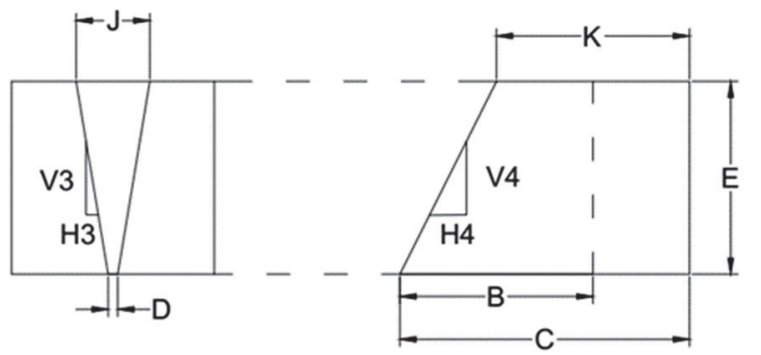

Front elevation

\section{Side elevation}

Figure 2. Diagram of $0.122 \mathrm{~m}$ HS flume.

(2006) for the $0.102 \mathrm{~m}$ Palmer-Bowlus flume (eq. 9) was also compared against similar flume types:

$$
Q=468.34 \times H^{1.9}
$$

where $Q$ is the flow rate $\left(\mathrm{L} \mathrm{s}^{-1}\right)$, and $H$ is the depth of water above the throat of the flume $(\mathrm{m})$.

All models fit the data well ( $\mathrm{R}^{2}$ adj $\left.>99 \%\right)$ except models 8 and 9 for the $0.122 \mathrm{~m} \mathrm{HS}$ flume (table 4). Model 9 is a previously published model and gave a lower $\mathrm{R}^{2}$ adj value and higher AIC and BIC values compared to the developed models. The dimensions of the flumes were slightly different between this study and the study by Bos (1976), so it was anticipated that model 9 would not be an appropriate model for these flumes. Here, model 3 was the best model for the combined PLA and PETG dataset for the $0.122 \mathrm{~m}$ HS flume based on the $\mathrm{AIC}_{\mathrm{ER}}$ (almost three times better than the second best model) and $\mathrm{BIC}_{\mathrm{ER}}(12$ times better than the second best model). The $\mathrm{AIC} w_{i}$ was also highest for model 3, and
Table 1. Dimensions of $0.122 \mathrm{~m}$ HS flume.

\begin{tabular}{ccc}
\hline & $\begin{array}{c}\text { Printed Value } \\
(\mathrm{cm})\end{array}$ & $\begin{array}{c}\text { Published Value } \\
(\text { Bos, 1976) } \\
(\mathrm{cm})\end{array}$ \\
\hline Dimension & 12.8016 & 12.81 \\
B & 12.9885 & 12.2 \\
C & 18.2814 & 18.3 \\
D & 0.6096 & 0.61 \\
E & 12.192 & 12.2 \\
F & 9.6393 & 12.8588 \\
G & 13.7084 & 12.8588 \\
H & 19.271 & 19.2882 \\
J & 6.7056 & 4.6726 \\
K & 9.1446 & 12.2 \\
H1:V1 & $1: 3$ & $1: 3$ \\
H2:V2 & $1: 1.266$ & $1: 1.897$ \\
H3:V3 & $1: 4$ & $1: 6$ \\
H4:V4 & $1: 1.33$ & $1: 2$ \\
\hline
\end{tabular}

Table 2. Dimensions of $0.102 \mathrm{~m}$ Palmer-Bowlus flume.

\begin{tabular}{ccc}
\hline Dimension & $\begin{array}{c}\text { Printed Value } \\
(\mathrm{cm})\end{array}$ & $\begin{array}{c}\text { Published Value } \\
\text { Walkowiak, 2006) } \\
(\mathrm{cm})\end{array}$ \\
\hline A & 10.16 & 10.2 \\
B & 16.2814 & 17.34 \\
C & 20.2692 & 20.4 \\
D & 10.16 & 10.2 \\
E & 5.1054 & 5.1 \\
F & 5.08 & 5.1 \\
G & 2.54 & 2.55 \\
J & 10.16 & Not provided \\
K & 1.6891 & 1.7 \\
\hline
\end{tabular}

Table 3. List of developed models, where $Q$ is the flow rate $\left(\mathrm{m}^{3} \mathrm{~s}^{-1}\right)$, and $H$ is the depth of the water level (m) at the point of measurement.

\begin{tabular}{ccc}
\hline Model & Equation & Type \\
\hline 1 & $Q=a+b \times H^{m}+c \times H^{n}$ & Linear regression \\
2 & $Q=a+b \times H^{m}$ & Linear regression \\
3 & $Q=a \times H^{m}$ & Linear regression \\
4 & $Q=a+b \times H^{0.5}+c \times H^{1.5}+d \times H^{2.5}$ & Linear regression \\
5 & $Q=P_{1} \times H^{2}+P_{2} \times H+P_{3}$ & Polynomial regression \\
6 & $Q=P_{1} \times H^{3}+P_{2} \times H^{2}+P_{3} \times H+P_{4}$ & Polynomial regression \\
7 & $Q=P_{1} \times H^{4}+P_{2} \times H^{3}+P_{3} \times H^{2}+P_{4} \times H+P_{5}$ & Polynomial regression \\
8 & $Q=a \times \exp (b \times H)$ & Exponential model \\
\hline
\end{tabular}

according to the $\mathrm{BIC} w_{i}$, there is a $91 \%$ probability that model 3 is the best model among the listed models to describe the measured data.

Model 2 was selected as the best model for the combined PLA and PETG dataset for the $0.102 \mathrm{~m}$ Palmer-Bowles flume (table 5) because it had lower AIC and BIC values as compared with the other models. Most of the models had similar $\mathrm{R}_{\text {adj }}^{2}$ values (>98\%) except models 8 and 9, where

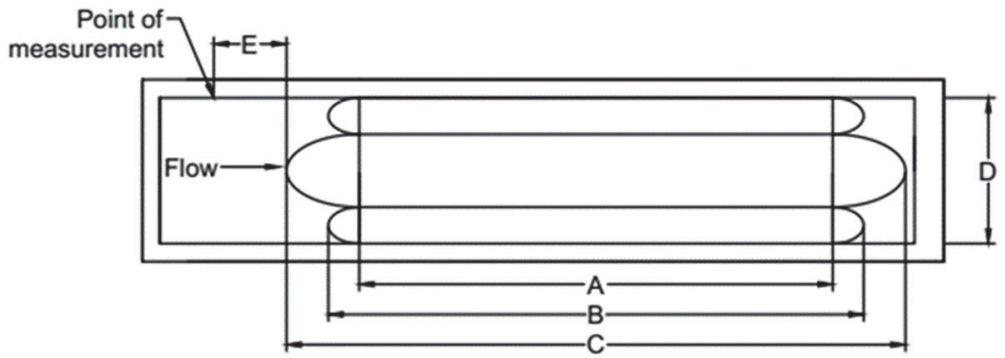

Plan view

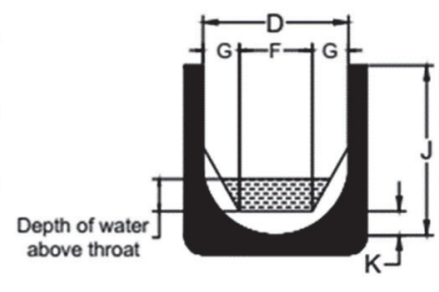

Elevation view

Figure 3. Diagram of 0.102 m Palmer-Bowlus flume. 
Table 4. Parameters, $\mathrm{R}^{2}$ adj, and results of AIC and BIC analysis of all models for 0.122 $\mathrm{m}$ HS flume (combined PLA and PETG dataset).

\begin{tabular}{|c|c|c|c|c|c|c|c|c|c|c|}
\hline Model & Equation & Parameters & $\mathrm{R}_{\text {adj }}^{2}$ & $\mathrm{AIC}$ & $\mathrm{AIC}_{c}$ & $\mathrm{AIC}_{\mathrm{ER}}$ & $\mathrm{AIC} w_{i}$ & $\mathrm{BIC}$ & $\mathrm{BIC}_{\mathrm{ER}}$ & $\mathrm{BIC} w_{i}$ \\
\hline 1 & $Q=a+b \times H^{m}+c \times H^{n}$ & $\begin{array}{c}a=1.3847 \times 10^{-5} \\
b=2.7304 \\
c=-3.7898 \\
m=2.7936 \\
n=3.2037\end{array}$ & 0.9940 & -2802.19 & -2801.91 & 4.52 & 0.12 & -2790.29 & 80.14 & 0.01 \\
\hline 2 & $Q=a+b \times H^{m}$ & $\begin{array}{c}a=-7.418 \times 10^{-7} \\
b=0.4545 \\
m=2.3493\end{array}$ & 0.994 & -2803.01 & -2802.84 & 2.83 & 0.19 & -2794.08 & 12.03 & 0.08 \\
\hline 3 & $Q=a \times H^{m}$ & $\begin{array}{l}a=0.45624 \\
m=2.3511\end{array}$ & 0.994 & -2805.01 & -2804.92 & 1.00 & 0.55 & -2799.05 & 1.00 & 0.91 \\
\hline 4 & $\begin{aligned} Q=a+ & b \times H^{0.5}+c \times H^{1.5} \\
& +d \times H^{2.5}\end{aligned}$ & $\begin{array}{c}a=4.308 \times 10^{-5} \\
b=-0.0005321 \\
c=0.01662 \\
d=0.5161\end{array}$ & 0.9938 & -2798.55 & -2798.11 & 30.08 & 0.02 & -2783.66 & 2197.9 & $4.1 \times 10^{-4}$ \\
\hline 5 & $Q=P_{1} \times H^{2}+P_{2} \times H+P_{3}$ & $\begin{array}{c}P_{1}=0.2649 \\
P_{2}=-0.00689 \\
P_{3}=7.217 \times 10^{-5}\end{array}$ & 0.9937 & -2797.04 & -2796.75 & 59.49 & 0.01 & -2785.13 & 1055.71 & $8.6 \times 10^{-4}$ \\
\hline 6 & $\begin{aligned} Q= & P_{1} \times H^{3}+P_{2} \times H^{2} \\
& +P_{3} \times H+P_{4}\end{aligned}$ & $\begin{array}{c}P_{1}=0.449 \\
P_{2}=0.1854 \\
P_{3}=-0.00296 \\
P_{4}=2.527 \times 10^{-5}\end{array}$ & 0.9938 & -2798.53 & -2798.1 & 30.35 & 0.02 & -2783.64 & 2217.88 & $4.1 \times 10^{-4}$ \\
\hline 7 & $\begin{array}{c}Q=P_{1} \times H^{4}+P_{2} \times H^{3} \\
+P_{3} \times H^{2}+P_{4} \times H+P_{5}\end{array}$ & $\begin{array}{c}P_{1}=-21.42 \\
P_{2}=5.551 \\
P_{3}=-0.2195 \\
P_{4}=0.009009 \\
P_{5}=-7.382 \times 10^{-5}\end{array}$ & 0.9940 & -2801.98 & -2801.37 & 5.90 & 0.09 & -2784.12 & 1747.66 & $5.2 \times 10^{-4}$ \\
\hline 8 & $Q=a \times \exp (b \times H)$ & $\begin{array}{c}a=4.371 \times 10^{-5} \\
b=38.45\end{array}$ & 0.9466 & -2487.43 & -2487.26 & $9.5 \times 10^{68}$ & $5.0 \times 10^{-70}$ & -2478.5 & $4.04 \times 10^{69}$ & $2.3 \times 10^{-70}$ \\
\hline 9 & $\begin{array}{c}\log Q=A+B\left(\log H_{a}\right) \\
+C\left(\log H_{a}\right)^{2}\end{array}$ & $\begin{array}{c}A=-0.4361 \\
B=2.5151 \\
C=0.1379\end{array}$ & 0.8589 & -2344.52 & -2344.24 & $1.1 \times 10^{100}$ & $5.0 \times 10^{-101}$ & -2332.62 & $1.9 \times 10^{101}$ & $4.7 \times 10^{-102}$ \\
\hline
\end{tabular}

Table 5. Parameters, $\mathbf{R}^{2}{ }_{\text {adj }}$, and results of AIC and BIC analysis of all models for 0.102 m Palmer-Bowlus (combined PLA and PETG dataset).

\begin{tabular}{|c|c|c|c|c|c|c|c|c|c|c|}
\hline Model & Equation & Parameters & $\mathrm{R}_{\text {adj }}^{2}$ & $\mathrm{AIC}$ & $\mathrm{AIC}_{c}$ & $\mathrm{AIC}_{\mathrm{ER}}$ & $\mathrm{AIC} w_{i}$ & $\mathrm{BIC}$ & $\mathrm{BIC}_{\mathrm{ER}}$ & $\mathrm{BIC} w_{i}$ \\
\hline 1 & $Q=a+b \times H^{m}+c \times H^{n}$ & $\begin{array}{c}a=0.0001186 \\
b=1.393 \\
c=-0.2259 \\
m=2.13 \\
n=1.91\end{array}$ & 0.9892 & -1627.15 & -1626.66 & 3.46 & 0.07 & -1617.24 & 10.82 & 0.07 \\
\hline 2 & $Q=a+b \times H^{m}$ & $\begin{array}{c}a=0.0001176 \\
b=1.309 \\
m=2.235\end{array}$ & 0.9894 & -1629.43 & -1629.15 & 1.00 & 0.26 & -1622.00 & 1.00 & 0.74 \\
\hline 3 & $Q=a \times H^{m}$ & $\begin{array}{c}a=0.7096 \\
m=2.002\end{array}$ & 0.9877 & -1618.47 & -1618.33 & 223.04 & 0.00 & -1613.52 & 69.47 & 0.01 \\
\hline 4 & $\begin{aligned} Q=a+ & b \times H^{0.5}+c \times H^{1.5} \\
& +d \times H^{2.5}\end{aligned}$ & $\begin{array}{c}a=-0.0004318 \\
b=0.005735 \\
c=-0.07167 \\
d=2.986\end{array}$ & 0.9895 & -1629.72 & -1628.98 & 1.08 & 0.24 & -1617.33 & 10.33 & $7.13 \times 10^{-2}$ \\
\hline 5 & $Q=P_{1} \times H^{2}+P_{2} \times H+P_{3}$ & $\begin{array}{c}P_{1}=0.8098 \\
P_{2}=-0.009078 \\
P_{3}=0.0001762\end{array}$ & 0.9888 & -1624.75 & -1624.27 & 11.44 & $2.24 \times 10^{-2}$ & -1614.84 & 35.80 & $2.06 \times 10^{-2}$ \\
\hline 6 & $\begin{aligned} Q= & P_{1} \times H^{3}+P_{2} \times H^{2} \\
& +P_{3} \times H+P_{4}\end{aligned}$ & $\begin{array}{c}P_{1}=8.202 \\
P_{2}=-0.1137 \\
P_{3}=0.02167 \\
P_{4}=-0.00011\end{array}$ & 0.9896 & -1629.85 & -1629.12 & 1.01 & 0.25 & -1617.46 & 9.67 & 0.08 \\
\hline 7 & $\begin{array}{c}Q=P_{1} \times H^{4}+P_{2} \times H^{3} \\
+P_{3} \times H^{2}+P_{4} \times H+P_{5}\end{array}$ & $\begin{array}{c}P_{1}=164.9 \\
P_{2}=-16.56 \\
P_{3}=1.169 \\
P_{4}=-0.004837 \\
P_{5}=6.838 \times 10^{-5}\end{array}$ & 0.9896 & -1629.23 & -1628.19 & 1.61 & 0.16 & -1614.36 & 45.51 & $1.62 \times 10^{-2}$ \\
\hline 8 & $Q=a \times \exp (b \times H)$ & $\begin{array}{c}a=0.000135 \\
b=49.37\end{array}$ & 0.9770 & -1564.34 & -1564.20 & $1.27 \times 10^{14}$ & $2.02 \times 10^{-15}$ & -1559.38 & $3.95 \times 10^{13}$ & $1.87 \times 10^{-14}$ \\
\hline 9 & $Q=468.34 \times H^{1.9}$ & - & 0.9489 & -1494.61 & -1494.47 & $1.75 \times 10^{29}$ & $1.46 \times 10^{-30}$ & -1489.66 & $5.47 \times 10^{28}$ & $1.35 \times 10^{-29}$ \\
\hline
\end{tabular}

model 9 was a previously published model (table 5). The dimensions of the flume used to develop the previously published discharge equation were slightly different from those presented in this study. The $\mathrm{AIC}_{\mathrm{ER}}$ and $\mathrm{BIC}_{\mathrm{ER}}$ showed that model 2 was nearly one time and ten times better, respectively, than the second-best model. The $\mathrm{AIC} w_{i}$ and $\mathrm{BIC} w_{i}$ showed that model 2 has the highest probability of being the best model. The chosen discharge equations for the three 
datasets (PLA, PETG, and combined PLA and PETG) for both flumes are given in table 6 .

\section{FLUME AND MATERIAL VARIABILITY}

The chosen models for each dataset (PLA, PETG, and combined PLA and PETG) were compared to the measured data for each individual flume. The goodness-of-fit parameters for each model and dataset (tables 7 and 8) show that the chosen models fit the measured data well, and there was no variability between materials nor among flumes of the same material. Because there was no variability between materials, a single calibration equation can be used. Overall, the discharge equations fit the measured data well, but there was more variability between the measured and predicted values at low and high flows (figs. 4 and 5). Robinson and Wright (1977) indicated similar results for a plexiglass HS flume. This was likely due to the boundary condition at low flows and the difficulty of measuring flow data at high flows. Due to the boundary condition at low flows, there was higher error in the measured flow data at depths below $7.62 \mathrm{~mm}$ for the $0.122 \mathrm{~m} \mathrm{HS}$ flume and below $26.543 \mathrm{~mm}$ for the $0.102 \mathrm{~m}$ Palmer-Bowlus flume. Therefore, the discharge equations are not valid below these depths. Because of no variability among the materials and the goodness-of-fit of the selected model for the combined PLA and PETG dataset, $Q=$ $0.45624 \times H^{2.351}$ and $Q=0.0001176+1.309 \times(H-$ $0.0174625)^{2.235}$ are considered the discharge equations for any similarly 3D printed $0.122 \mathrm{~m}$ HS flume and $0.102 \mathrm{~m}$ Palmer-Bowlus flumes, respectively.

\section{Conclusions}

This study developed two discharge equations for 3D printed $0.122 \mathrm{~m}$ HS and $0.102 \mathrm{~m}$ Palmer-Bowlus flumes and demonstrated that the discharge equations were consistent between printing materials and among flumes of the same type. While the bucket method to determine mass flow rate was effective, future research could be performed with an improved method to improve the consistency of the measured data at low and high flows. A tank of a known area with a staff gauge can be used to measure the flow rate instead of the bucket method, which will reduce the difficulty of flow data collection. While the results indicated that flume measurements and flow relationships were consistent, the equations were developed using new flumes. It is currently unknown how the discharge equations or other flume characteristics could change after deployment in field conditions.

While this study demonstrated that $3 \mathrm{D}$ printed flumes provide an accurate, reliable flow monitoring tool, future work could be used to optimize the printing characteristics, such as layer height, nozzle diameter, and print orientation. Current 3D printing technology can provide small flumes in less than two days and inexpensively ( $\$ 50$ or less for materials). However, future research should include ways to

Table 6. Chosen discharge equations for three datasets for $0.122 \mathrm{~m}$ HS flume and $0.102 \mathrm{~m}$ Palmer-Bowles flume, where $Q$ is the volumetric flow rate $\left(\mathrm{m}^{3} \mathrm{~s}^{-1}\right)$, and $H$ is the depth of the water level $(\mathrm{m})$ at the point of measurement.

\begin{tabular}{ccc}
\hline Dataset & $0.122 \mathrm{~m} \mathrm{HS} \mathrm{Flume}{ }^{[\mathrm{a}]}$ & $0.102 \mathrm{~m}$ Palmer-Bowles Flume \\
\hline PLA & $Q=0.4399 \times H^{2.331}$ & $Q=0.0001071+1.288 \times(H-0.0174625)^{2.229}$ \\
PETG & $Q=0.4751 \times H^{2.373}$ & $Q=0.0001308+1.370 \times(H-0.0174625)^{2.251}$ \\
Combined PLA and PETG & $Q=0.45624 \times H^{2.351}$ & $Q=0.0001176+1.309 \times(H-0.0174625)^{2.235}$ \\
\hline
\end{tabular}

[a] Equations are not valid at flow depths less than $7.62 \mathrm{~mm}$.

[b] Equations are not valid at flow depths less than $26.543 \mathrm{~mm}$.

Table 7. Goodness-of-fit of selected models for PLA, PETG, and combined PLA and PETG datasets (0.122 m HS flume).

\begin{tabular}{cccccccc}
\hline \multirow{2}{*}{ Statistic } & Dataset & \multicolumn{5}{c}{ Test Flume (and Material) } \\
\cline { 3 - 7 } $\mathrm{R}^{2}{ }_{\text {adj }}$ & Plume-1 (PLA) & Flume-2 (PLA) & Flume-3 (PLA) & Flume-1 (PETG) & Flume-2 (PETG) & Flume-3 (PETG) \\
& PETG & 0.990 & 0.979 & 0.995 & 0.997 & 0.998 & 0.996 \\
& PLA and PETG & 0.987 & 0.980 & 0.994 & 0.998 & 0.998 & 0.999 \\
\hline SSE & PLA & $1.28 \times 10^{-7}$ & $2.67 \times 10^{-7}$ & $7.73 \times 10^{-8}$ & $4.33 \times 10^{-8}$ & $1.87 \times 10^{-8}$ & $5.54 \times 10^{-8}$ \\
& PETG & $1.67 \times 10^{-7}$ & $2.61 \times 10^{-7}$ & $1.03 \times 10^{-7}$ & $2.19 \times 10^{-8}$ & $2.11 \times 10^{-8}$ & $1.49 \times 10^{-8}$ \\
& PLA and PETG & $1.42 \times 10^{-7}$ & $2.59 \times 10^{-7}$ & $8.53 \times 10^{-8}$ & $2.79 \times 10^{-8}$ & $1.52 \times 10^{-8}$ & $3.02 \times 10^{-8}$ \\
\hline RMSE & PLA & $7.99 \times 10^{-5}$ & $1.03 \times 10^{-4}$ & $5.45 \times 10^{-5}$ & $4.16 \times 10^{-5}$ & $2.79 \times 10^{-5}$ & $4.71 \times 10^{-5}$ \\
& PETG & $9.13 \times 10^{-5}$ & $1.02 \times 10^{-4}$ & $6.29 \times 10^{-5}$ & $2.96 \times 10^{-5}$ & $2.97 \times 10^{-5}$ & $2.45 \times 10^{-5}$ \\
& PLA and PETG & $8.42 \times 10^{-5}$ & $1.02 \times 10^{-4}$ & $5.73 \times 10^{-5}$ & $3.34 \times 10^{-5}$ & $2.52 \times 10^{-5}$ & $3.47 \times 10^{-5}$ \\
\hline
\end{tabular}

Table 8. Goodness-of fit-of selected models for PLA, PETG, and combined PLA and PETG datasets (0.102 m Palmer-Bowlus flume).

\begin{tabular}{|c|c|c|c|c|c|c|c|}
\hline \multirow[b]{2}{*}{ Statistic } & \multirow[b]{2}{*}{ Dataset } & \multicolumn{6}{|c|}{ Test Flume (and Material) } \\
\hline & & Flume-1 (PLA) & Flume-2 (PLA) & Flume-3 (PLA) & Flume-1 (PETG) & Flume-2 (PETG) & Flume-3 (PETG) \\
\hline \multirow{3}{*}{$\mathrm{R}_{\text {adj }}^{2}$} & PLA & 0.996 & 0.993 & 0.989 & 0.990 & 0.9705 & 0.9937 \\
\hline & PETG & 0.995 & 0.991 & 0.990 & 0.987 & 0.9765 & 0.9919 \\
\hline & PLA and PETG & 0.995 & 0.992 & 0.990 & 0.989 & 0.975 & 0.9931 \\
\hline \multirow[t]{3}{*}{ SSE } & PLA & $5.02 \times 10^{-8}$ & $9.37 \times 10^{-8}$ & $1.46 \times 10^{-7}$ & $1.19 \times 10^{-7}$ & $3.00 \times 10^{-7}$ & $6.86 \times 10^{-8}$ \\
\hline & PETG & $6.50 \times 10^{-8}$ & $1.27 \times 10^{-7}$ & $1.30 \times 10^{-7}$ & $1.50 \times 10^{-7}$ & $2.40 \times 10^{-7}$ & $8.84 \times 10^{-8}$ \\
\hline & PLA and PETG & $6.41 \times 10^{-8}$ & $1.32 \times 10^{-7}$ & $1.57 \times 10^{-7}$ & $1.32 \times 10^{-7}$ & $2.73 \times 10^{-7}$ & $7.58 \times 10^{-8}$ \\
\hline \multirow[t]{3}{*}{ RMSE } & PLA & $5.78 \times 10^{-5}$ & $7.42 \times 10^{-5}$ & $9.54 \times 10^{-5}$ & $8.66 \times 10^{-5}$ & $1.42 \times 10^{-4}$ & $6.76 \times 10^{-5}$ \\
\hline & PETG & $6.58 \times 10^{-5}$ & $8.64 \times 10^{-5}$ & $9.02 \times 10^{-5}$ & $9.69 \times 10^{-5}$ & $1.27 \times 10^{-4}$ & $7.68 \times 10^{-5}$ \\
\hline & PLA and PETG & $6.33 \times 10^{-5}$ & $8.33 \times 10^{-5}$ & $9.34 \times 10^{-5}$ & $9.08 \times 10^{-5}$ & $1.35 \times 10^{-4}$ & $7.11 \times 10^{-5}$ \\
\hline
\end{tabular}




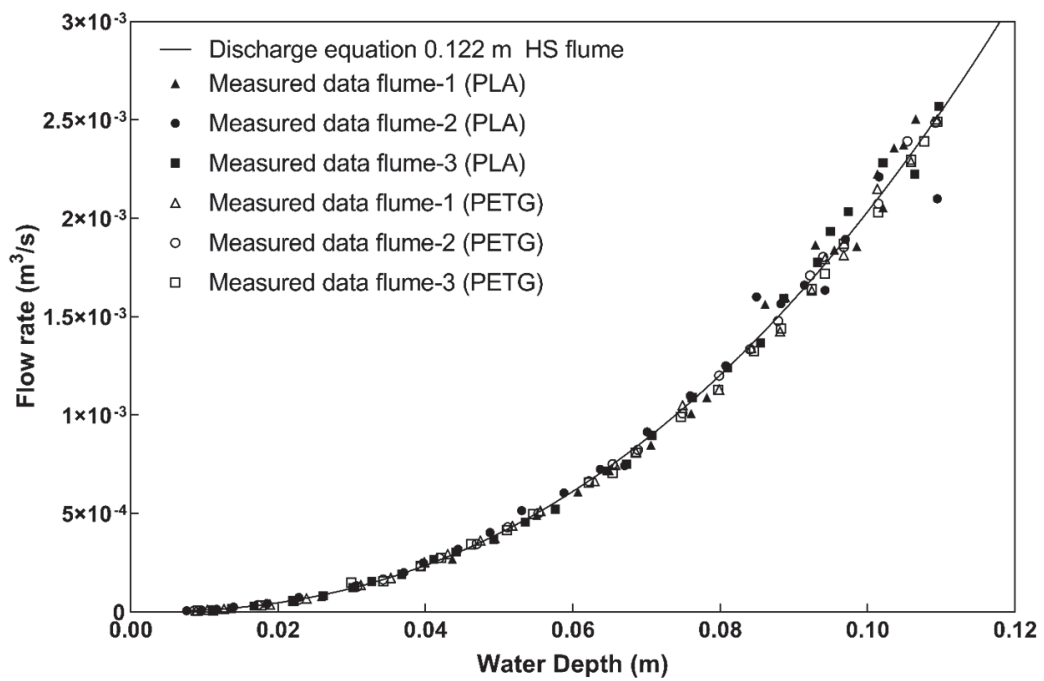

Figure 4. Selected model for $0.122 \mathrm{~m}$ HS flume.

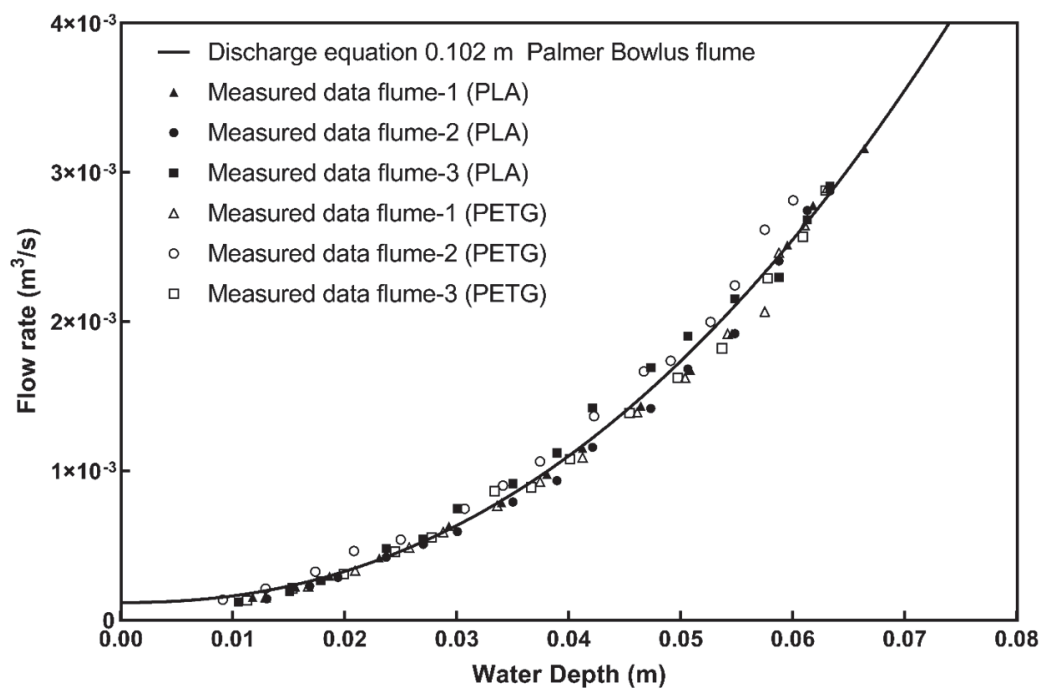

Figure 5. Selected model for 0.102 m Palmer-Bowlus flume.

integrate low-cost sensors with 3D printed flumes to enable truly low-cost solutions for stormwater runoff monitoring.

\section{ACKNOWLEDGEMENTS}

The authors would like to acknowledge partial funding support from an EPA 319 Information and Education minigrant, the East Dakota Water Development District, and South Dakota Agricultural Experiment Station Hatch Project SD00H652-18. The authors would also like to acknowledge Jeff Vander Schaff and Blake Wolters for technical assistance in implementing the testing apparatus.

\section{REFERENCES}

Akaike, H. (1974). A new look at the statistical model identification. IEEE Trans. Automatic Control, 19(6), 716-723. https://doi.org/10.1109/TAC.1974.1100705

Bos, M. G. (1976). Discharge measurement structures. Publication 20. The Hague, Netherlands: International Institute for Land Reclamation and Improvement.
Burnham, K. P., \& Anderson, D. R. (2002). Model selection and multimodel inference: A practical information-theoretic approach (2nd Ed.). New York, NY: Springer.

Gwinn, W. R., \& Parsons, D. A. (1976). Discharge equations for HS, H, and HL flumes. J. Hydraul. Div., 102(1), 73-88. https://doi.org/10.1061/JYCEAJ.0004474

Holtan, H. N., Minshall, N. E., \& Harrold, L. L. (1962). Field manual for research in agricultural hydrology. Agricultural Handbook 224. Washington, DC: USDA Soil and Water Conservation Research Division.

Hurvich, C. M., \& Tsai, C.-L. (1989). Regression and time series model selection in small samples. Biometrika, 76(2), 297-307. https://doi.org/10.1093/biomet/76.2.297

Kass, R. E., \& Raftery, A. E. (1995). Bayes factors. J. American Stat. Assoc., 90(430), 773-795. https://doi.org/10.1080/01621459.1995.10476572

Kilpatrick, F. A., \& Schneider, V. R. (1983). Use of flumes in measuring discharge: USGS Techniques of Water-Resources Investigations, Book 3, Chapter A-14. Reston, VA: U.S. Geological Survey.

Ludwig, R. G., \& Parkhurst, J. D. (1974). Simplified application of Palmer-Bowlus flow meters. J. Water Pollut. Control Fed., 46(12), 2764-2769. 
Manross, R. C. (1985). Wastewater treatment plant instrumentation handbook. Springfield, VA: Nattional Technical Information Services.

Palmer, H. K., \& Bowlus, F. D. (1936). Adaptation venturi flumes to flow conduits. Trans. ASCE, 101(1), 1195-1216. https://doi.org/10.1061/TACEAT.0004761

Richards, S. A. (2005). Testing ecological theory using the information-theoretic approach: Examples and cautionary results. Ecology, 86(10), 2805-2814. https://doi.org/10.1890/050074

Robinson Jr, W. H., \& Wright, M. E. (1977). A note on plexiglas HS flumes. Water Resour. Res., 13(1), 211-212.

https://doi.org/10.1029/WR013i001p00211
Schwarz, G. (1978). Estimating the dimension of a model. Ann. Stat., 6(2), 461-464. https://doi.org/10.1214/aos/1176344136

Symonds, M. R., \& Moussalli, A. (2011). A brief guide to model selection, multimodel inference, and model averaging in behavioural ecology using Akaike's information criterion. Behav. Ecol. Sociobiol., 65(1), 13-21. https://doi.org/10.1007/s00265-010-1037-6

Wagenmakers, E.-J., \& Farrell, S. (2004). AIC model selection using Akaike weights. Psychonomic Bull. Rev., 11(1), 192-196. https://doi.org/10.3758/BF03206482

Walkowiak, D. K. (2006). ISCO open-channel flow measurement handbook. Lincoln, NE: Teledyne ISCO. 